\title{
Assessment of long-term impact of formal certified cardiopulmonary resuscitation training program among nurses
}

\author{
P. P. Saramma, L. Suja Raj', P. K. Dash², P. S. Sarma ${ }^{3}$
}

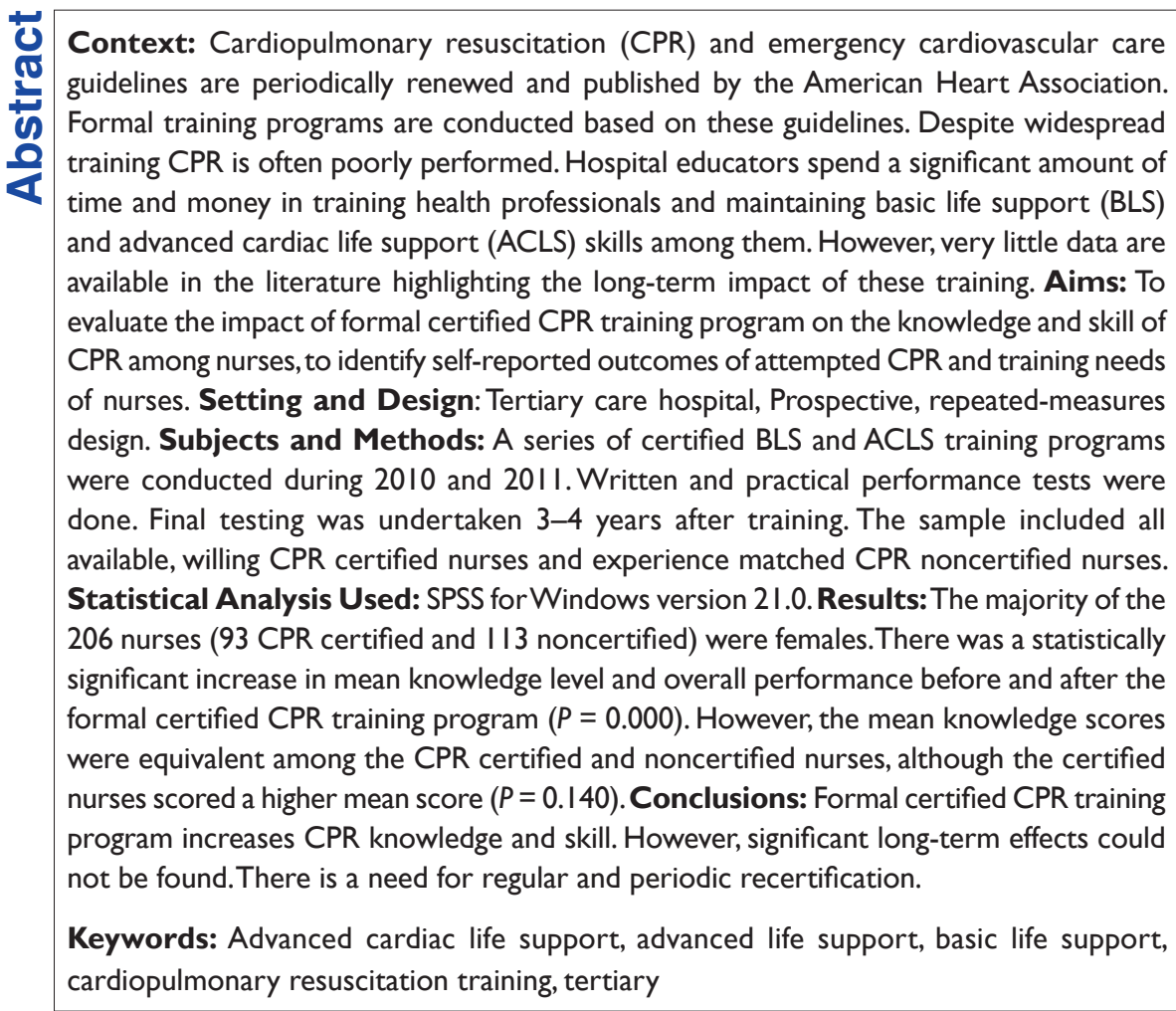

Access this article online

Website: www.ijccm.org

DOI: 10.4103/0972-5229.180043

Quick Response Code:

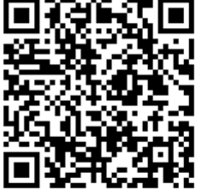

\section{Introduction}

Early cardiopulmonary resuscitation (CPR) of cardiac arrest victims can improve the likelihood of survival.

From:

Division of Nursing Education, Sree Chitra Tirunal Institute for Medical

Sciences and Technology, ${ }^{1}$ Division of Nursing Service, Sree Chitra

Tirunal Institute for Medical Sciences and Technology, ${ }^{2}$ Department of

Anaesthesiology, Sree Chitra Tirunal Institute for Medical Sciences and

Technology, ${ }^{3}$ Achutha Menon Centre for Health Science Studies, Sree Chitra

Tirunal Institute for Medical Sciences and Technology, Thiruvananthapuram,

Kerala, India

Correspondence:

Dr. P. P. Saramma, Sree Chitra Tirunal Institute for Medical Sciences

and Technology, Thiruvananthapuram - 695 011, Kerala, India.

E-mail: ins@sctimst.ac.in
The foundation for CPR is basic life support (BLS). ${ }^{[1]}$ Clinical experience alone does not enable healthcare professionals to maintain or increase competency in BLS or advanced cardiac life support (ACLS) ${ }^{[2]} \mathrm{CPR}$ is often

This is an open access article distributed under the terms of the Creative Commons Attribution-NonCommercial-ShareAlike 3.0 License, which allows others to remix, tweak, and build upon the work non-commercially, as long as the author is credited and the new creations are licensed under the identical terms.

For reprints contact: reprints @ medknow.com

How to cite this article: Saramma PP, Raj LS, Dash PK, Sarma PS. Assessment of long-term impact of formal certified cardiopulmonary resuscitation training program among nurses. Indian J Crit Care Med 2016;20:226-32. 
poorly performed despite widespread training according to the guidelines. ${ }^{[3]}$ Hospital employed registered nurses must be proficient in BLS and advanced life support (ALS) to detect and manage emergencies. Hospital educators spend a significant amount of time training and maintaining biennial BLS courses for hospital nurses and other health care providers. However, there are several variables that might affect skill retention, including instructor variations, too much time between the course and actual practice, the complexity of the skill being taught, lack of supervision and feedback during learning, and insufficient practice.$^{[4]} \mathrm{CPR}$ and emergency cardiovascular care guidelines are regularly renewed and published by the American Heart Association (AHA) and European regulation council (ERC). Formal training programs are conducted based on these guidelines. Formal certified BLS and ACLS training of healthcare professionals lead to definitive improvements in the outcome of CPR. ${ }^{[5]}$ However, very few evaluative studies are available in the literature. This study is undertaken to evaluate the long-term impact of formal certified CPR training program among nurses in a tertiary level referral superspecialty hospital in India and to identify self-reported outcomes of attempted CPR and training needs of nurses.

\section{Subjects and Methods}

This prospective study used a repeated measure design. The intervention was a formally certified BLS and ACLS training program to hospital-employed registered nurses, conducted in a 253 bedded, tertiary level referral superspecialty hospital in Kerala, India. The study was conducted in two phases. In the first phase, a series of certified BLS and ACLS training programs were conducted. The subjects were registered nurses who were randomly selected by the nursing service division, one each from different units of the hospital, to attend any one of the 12 training courses- $20 \mathrm{~h}$ of intense CPR training over a period of 10 days. Twelve batches, with 12-14 nurses per batch, completed the training during 2010-2011. Certificates were issued to those who have completed the pretest, attended all the classes, and who scored at least 70\% aggregate in the posttest written knowledge test and performance test using a CPR simulator or mannequin. The names and primary work units of top scorers of each batch were displayed on notice boards as an incentive to the participants, and certificates were issued in a public meeting. One hundred and fifty-two nurses (approximately $60 \%$ of the target population) got certified.

In the second phase, after Institutional Ethics Committee approval and informed consent from participants, all available CPR certified nurses and experience matched CPR noncertified nurses were interviewed using a semi-structured interview schedule to evaluate the long-term impact of formal certified CPR training programs on CPR knowledge and skill among nurses, to identify self-reported outcomes of attempted CPR, and training needs of nurses. Data were collected through face to face interview at the nurses' convenience in an office setting. Period of the study was for 3 months, September - November 2014. Two hundred and six hospital-employed registered nurses, 93 CPR certified nurses and 113 noncertified nurses (approximately 80\% of target population) completed the study.

\section{Program intervention}

The CPR training was a 10 -day $(20 \mathrm{~h})$ program planned by the nursing service, nursing education and the department of anesthesiology, and approved by the higher authorities. It included both BLS and ACLS, imparting both theoretical knowledge and simulated practice sessions. The program was conducted by a resuscitation team including six anesthetists, one cardiologist, one neurologist, and one nursing faculty who shared the responsibility of the training; thus maintaining the homogeneity of training. A resuscitation team E-mail ID was created for easy communication among team members. The "Heartsim-4000 Interactive ACLS mannequin" (CPR simulator) was used for simulation. It is a life-size mannequin used for giving training in BLS and ACLS and has computer integrated Arrhythmia detection facility. Its chest rises and falls with breathing and trachea can be intubated. It has breath sounds and palpable carotid pulse. It has the facility for defibrillation, intravenous (IV) line insertion, and IV fluid administration. Chest compression rate, depth, and rhythm, bag mask ventilation volume and rate, as well as compression to ventilation ratio were monitored during practicing as well as performance testing. In addition to the CPR simulator, a defibrillator, a ventilator, endotracheal tubes, tracheostomy tubes, airways, manual breathing units, face masks, syringes and cannulas, and a portable oxygen cylinder were used to provide hands-on practice as and when necessary. The topics covered included: CPR-an overview: BLS and ACLS, Peripheral venous cannulation and management of invasive Catheters, Artificial airway and bag-mask ventilation, $\mathrm{O}_{2}$ therapy, Chest compression and defibrillation, Basic ECG reading and diagnosis of life-threatening arrhythmias, ACLS algorithms and drug therapy, Arrangement of emergency carts and organization of resuscitation team, Resuscitation in special situations, Postresuscitation care and communication skill, and a mock drill practice session. These topics were covered using lectures, 
demonstrations, return demonstrations, and hands-on practice on a simulator in a clinical lab/classroom. The training program was initiated on February 15, 2010 with the enrollment of the first batch of nurses and ended on October 14, 2011, with the twelfth batch of nurses.

\section{Outcome variables}

\section{Knowledge test}

A 50-item, 50 min long, objective type test was administered to measure knowledge about BLS and ACLS at the beginning and end of each course (preand post-training knowledge tests). A set of objective type questions along with answers were prepared and E-mailed to the evaluation team by each faculty based on the course content covered by them, and tests were compiled by the evaluation faculty, experienced in teaching and evaluation of students, based on the importance, accuracy and appropriateness of each question and answer. The pretests and posttests were similar for each batch. However, the questions were changed to maintain the objectivity of the tests for different batches. Moreover, the participants were given strict instructions not to disclose the questions to colleagues. The pretests and posttests were conducted and evaluated by the same faculty from the resuscitation team, using content validated tests. A score of $60 \%$ was required to pass the written test.

\section{Performance test}

A performance test on specific BLS and ACLS skills of 50 scores was conducted on a one-to-one basis towards the end of each ten day training (post-training performance test) program. The performance skills evaluated included demonstrating the BLS algorithm (assessing unresponsiveness, checking carotid pulse, hand location for external cardiac compression, effective cardiac compression, airway opening techniques, and rescue breaths using the bag-mask technique). Some of the ACLS skills evaluated were the identification of shockable rhythms, proper use of a biphasic defibrillator, introducing oropharyngeal airway, and selection of IV cannula and drugs dosage. The same practical scenarios were used for all participants and were conducted using CPR simulator or mannequin and other medical equipment used for the training program. The participants were evaluated two at a time by two faculty members; each one evaluating different clinical performances of BLS and ACLS. Rate and depth of compressions, rate and volume of ventilations and compression-ventilation ratio were evaluated using the simulator. Observation checklists were used to maintain the objectivity of evaluation. The performance test took 30 min per participant. A score of $80 \%$ was required to pass the performance test. The overall performance was calculated based on an average of post-training knowledge score and performance score and a score of $70 \%$ was set as a pass mark for overall performance.

\section{Retest}

A six item objective type knowledge test covering six cardinal aspects of BLS as per 2010 AHA guidelines was used. The questions included the sequence of $\mathrm{CPR}$, compression to ventilation ratio in one-rescuer adult CPR, as well as child CPR, the rate of cardiac compression in adult CPR, as well as child CPR, and the depth in centimeters of external cardiac compression in adult CPR. This was done as part of a semi-structured interview schedule included in the second phase of the study in 2014.

\section{Data analysis}

All the quantitative data were entered and analyzed using SPSS for Windows version 21.0. Descriptive statistics were used to summarize the demographic information and to compare the proportion of participants who passed the written tests. Paired $t$-test was used to evaluate the differences between pretest and posttest and Spearman's rho correlation was used to assess changes in knowledge over time since the retest included only six salient aspects of BLS. Statistical significance was set at $P<0.05$.

\section{Results}

The majority of the participant nurses were females similar to the target population of hospital employed registered nurses. Demographic data are presented in Table 1.

The experience of 152 hospital employed nurses in phase one, ranged from 6 months to 32 years. Table 2 lists the means and standard deviations for the pre- and post-training knowledge score and performance score of $\mathrm{CPR}$ trained nurses. The pretest knowledge score ranged from 9 to 44, the posttest knowledge score ranged from 27 to 47 , the posttest performance score ranged from 26 to 48 and the overall performance score ranged from 28 to 46 , out of 50 . There was a statistically significant increase in mean knowledge and overall performance before and after formal certified CPR training. Only 54 nurses $(35.5 \%)$ passed (scored $>60 \%$ ) in the pretest, whereas $142(93.4 \%)$ nurses passed in the posttest knowledge test. However, only 89 (58.6\%) nurses passed (scored $>80 \%$ ) in the performance test which was conducted only once, after the training program. With regards to overall performance 126 (82.9\%) nurses passed (scored 


\begin{tabular}{|c|c|c|c|c|}
\hline \multirow[t]{2}{*}{ Characteristics } & \multirow{2}{*}{$\begin{array}{c}\text { Phase I } \\
(n=I 52) \\
\text { Nurses } \\
n(\%)\end{array}$} & \multicolumn{3}{|c|}{$\begin{array}{l}\text { Phase } 2 \\
(n=206)\end{array}$} \\
\hline & & $\begin{array}{c}\text { CPR } \\
\text { certified } \\
n(\%)\end{array}$ & $\begin{array}{c}\text { CPR } \\
\text { noncertified } \\
n(\%)\end{array}$ & $P^{*}$ \\
\hline \multicolumn{5}{|l|}{ Gender, $n$ (\%) } \\
\hline Female & I36 (89.5) & $84(90.3)$ & $102(90.3)$ & 0.989 \\
\hline Male & $16(10.5)$ & $9(9.7)$ & II (9.7) & \\
\hline \multicolumn{5}{|l|}{ Professional qualification } \\
\hline Diploma & $51(33.6)$ & $30(32.3)$ & $39(34.5)$ & 0.003 \\
\hline Bachelor's degree & $44(28.9)$ & $29(31.2)$ & $55(48.7)$ & \\
\hline $\begin{array}{l}\text { Master's degree/ } \\
\text { specialization }\end{array}$ & $57(37.5)$ & $34(36.6)$ & $19(16.8)$ & \\
\hline \multicolumn{5}{|l|}{ Primary work unit } \\
\hline $\begin{array}{l}\text { Neurology/ } \\
\text { neurosurgery }\end{array}$ & $70(46.1)$ & $40(43)$ & $5 I(45.1)$ & 0.760 \\
\hline $\begin{array}{l}\text { Cardiology/cardiac } \\
\text { surgery }\end{array}$ & $82(53.9)$ & $53(57)$ & $62(54.9)$ & \\
\hline \multicolumn{5}{|l|}{ Type of unit } \\
\hline $\begin{array}{l}\text { Wards/outpatient } \\
\text { services }\end{array}$ & $81(53.3)$ & $53(57)$ & $64(56.6)$ & 0.960 \\
\hline Critical care units & 7I (46.7) & $40(43)$ & $49(43.4)$ & \\
\hline Total & $152(100)$ & $93(100)$ & $113(100)$ & \\
\hline $\begin{array}{l}\text { Experience in years } \\
{[\text { Mean (SD)] }}\end{array}$ & $12.64(10.89)$ & $14.22(10.20)$ & $12.18(9.14)$ & 0.132 \\
\hline $\begin{array}{l}\text { ICU experience in years } \\
\text { [Mean (SD)] }\end{array}$ & & $7.55(7.87)$ & $6.08(6.28)$ & 0.138 \\
\hline
\end{tabular}

Table 2: Mean pre- and post-test Knowledge and performance score $(n=152)$

\begin{tabular}{lcc}
\hline $\begin{array}{l}\text { Pre- and post-test } \\
\text { knowledge/skill score }\end{array}$ & Mean (SD) & $\begin{array}{c}\text { Significant } \\
\text { (two-tailed) }\end{array}$ \\
\hline Pretest knowledge score & $26.36(7.384)$ & 0.000 \\
Posttest knowledge score & $36.35(4.363)$ & 0.000 \\
Pretest knowledge score & $26.36(7.384)$ & 0.000 \\
Posttest performance score & $40.39(4.322)$ & \\
Pretest knowledge score & $26.36(7.384)$ & \\
Overall performance score & $38.32(3.565)$ & \\
\hline
\end{tabular}

SD: Standard deviation

$>70 \%)$ while $26(17.1 \%)$ failed. The pass percentage among different tests and significant association with demographic variables are given in Table 3. The pass percent of those who work in critical care units, with graduation, postgraduation or specialization, and with $<10$ years' experience was significantly higher than their counterparts [Table 3].

There was a significant positive correlation between pretest knowledge score and posttest knowledge scores $(r=0.437, P=0.000)$ pretest knowledge score and overall performance score $(r=0.523, P=0.000)$.

Two hundred and six hospital-employed registered nurses (93 CPR certified and 113 noncertified), completed the survey in phase two. The experience of these nurses ranged from 6 months to 30 years. The information given in Table 1 shows that the groups were similar in all demographic characteristics like their experience, gender, primary work unit or type of unit. However, the percentage of postgraduate nurses and specialized nurses were significantly higher among the CPR certified nurses $(P=0.003)$.

All the 93 CPR certified nurses agreed that the training was useful. Eighty-two percent told that it increased their knowledge, $78 \%$ reported that it increased their skill, 56\% told that it improved their attitude. A further $48 \%$ agreed that it improved their communication while $69 \%$ confirmed that it increased their confidence. The reported outcome of CPR performance is given in Table 4. There was no significant difference between certified and noncertified nurses in any of the characteristics except observing 2010 AHA guidelines being followed during CPR. A significantly higher percent of CPR certified nurses reported affirmatively while the noncertified nurses reported negatively.

In phase two, the knowledge scores ranged from 0 to 6 , in both the groups, with six being the maximum obtainable score. Table 5 lists the means and standard deviations for the CPR knowledge retest of CPR certified nurses and noncertified nurses. The average scores were not significantly different between the two groups, although the certified group scored a higher mean score. When mean knowledge on the six individual questions was compared, a statistically significant difference was obtained for the question regarding the depth in centimeter of external cardiac compression in adult CPR. Approximately $64 \%$ of the CPR certified nurses answered correctly whereas only $37 \%$ of noncertified nurses could answer it correctly $(P=0.017)$. In addition, there was a significant correlation between the mean pretest knowledge score and the retest knowledge score of the 93 CPR certified nurses $(r=0.222, P=0.038)$.

Regarding necessity for periodic CPR training, all the participants agreed unanimously to it. However there was the difference in the needed periodicity of the CPR training and it ranged from 6 months to 5 years. However, the majority of the participants in CPR certified group (65\%) and the noncertified group (68\%) wanted yearly CPR training. When asked about measures to improve CPR techniques, 31 CPR certified nurses and 25 noncertified nurses suggested periodic training whereas 21 CPR certified nurses and 25 noncertified nurses suggested having a code blue system in place $(P=1.0)$. The majority did not answer this question. 


\begin{tabular}{|c|c|c|c|}
\hline Tests & Passed n (\%) & Failed $n(\%)$ & $P$ \\
\hline \multicolumn{4}{|l|}{ Pretest } \\
\hline Critical care units & $32(45.1)$ & $39(54.9)$ & \multirow[t]{2}{*}{0.021} \\
\hline Wards/outpatient services & $22(27.2)$ & $59(72.8)$ & \\
\hline \multicolumn{4}{|l|}{ Overall performance } \\
\hline Critical care units & $48(67.6)$ & $23(32.4)$ & \multirow[t]{2}{*}{0.034} \\
\hline Wards/outpatient services & $41(50.6)$ & $40(49.4)$ & \\
\hline \multicolumn{4}{|l|}{ Posttest } \\
\hline Diploma & $44(86.3)$ & $7(13.7)$ & \multirow[t]{3}{*}{0.040} \\
\hline Bachelor's degree & $43(97.7)$ & $\mathrm{I}(2.3)$ & \\
\hline Master's degree/specialization & $55(96.5)$ & $2(3.5)$ & \\
\hline \multicolumn{4}{|l|}{ Pretest (years) } \\
\hline Experience $<10$ & $37(46.3)$ & $43(53.8)$ & \multirow[t]{4}{*}{0.026} \\
\hline $10-20$ & $4(22.2)$ & I4 (77.8) & \\
\hline $20-30$ & $13(25.5)$ & $38(74.5)$ & \\
\hline$>30$ & 0 & $3(100)$ & \\
\hline \multicolumn{4}{|l|}{ Overall performance (years) } \\
\hline Experience $<10$ & $74(92.5)$ & $6(7.5)$ & \multirow[t]{3}{*}{0.011} \\
\hline $10-20$ & $13(72.2)$ & $5(27.8)$ & \\
\hline $20-30$ & $37(72.5)$ & $14(27.5)$ & \\
\hline$>30$ & $2(66.7)$ & I (33.3) & \\
\hline
\end{tabular}

Table 4: Cardiopulmonary resuscitation performance and result during last 2 years $(n=206)$

\begin{tabular}{|c|c|c|c|}
\hline Characteristics & $\begin{array}{c}\text { CPR certified } \\
n(\%)\end{array}$ & $\begin{array}{c}\text { CPR noncertified } \\
n(\%)\end{array}$ & $P$ \\
\hline \multicolumn{4}{|l|}{ Given CPR } \\
\hline Yes & $44(47.3)$ & $49(43.4)$ & 0.571 \\
\hline No & $49(52.7)$ & $64(56.6)$ & \\
\hline \multicolumn{4}{|c|}{$\begin{array}{l}\text { Participated as a CPR team } \\
\text { member }\end{array}$} \\
\hline Yes & $58(62.4)$ & $62(54.9)$ & 0.277 \\
\hline No & $35(37.6)$ & $5 I(45.1)$ & \\
\hline \multicolumn{4}{|l|}{ CPR outcome } \\
\hline Success & 53 & 54 & 0.426 \\
\hline poor & 14 & 20 & \\
\hline \multicolumn{4}{|c|}{ Awareness 2010 AHA guidelines } \\
\hline Yes & $73(80.2)$ & $80(70.8)$ & 0.122 \\
\hline No & $18(19.8)$ & $33(29.2)$ & \\
\hline \multicolumn{4}{|c|}{ Observed CPR performance } \\
\hline Yes & $86(92.5)$ & $102(90.3)$ & 0.577 \\
\hline No & $7(7.5)$ & II (9.7) & \\
\hline \multicolumn{4}{|c|}{$\begin{array}{l}\text { Observed } 2010 \text { AHA guidelines } \\
\text { being followed }\end{array}$} \\
\hline Yes & 6I (65.6) & $47(4 \mid .6)$ & 0.001 \\
\hline No & $32(34.4)$ & $66(58.4)$ & \\
\hline
\end{tabular}

Table 5: Mean retest knowledge score of cardiopulmonary resuscitation certified nurses and noncertified nurses

\begin{tabular}{lccc}
\hline Group & $n$ & Mean (SD) & $\boldsymbol{P}$ \\
\hline CPR certified nurses & 93 & $3.59(1.990)$ & 0.140 \\
Noncertified nurses & 113 & $3.19(1.930)$ & \\
\hline
\end{tabular}

SD: Standard deviation; CPR: Cardiopulmonary resuscitation

\section{Discussion}

The purpose of this study was to evaluate the long-term impact of formal certified CPR training program among hospital-employed registered nurses in a tertiary level referral superspecialty hospital in India and to identify self-reported outcomes of attempted CPR and training needs of nurses. Teaching methods for CPR vary-including simulation training, E-learning and lecture based courses ${ }^{[6]}$ Learning by teaching is another strategy to teach CPR among medical students. ${ }^{[7]}$ In order to develop complex critical care skills like CPR, simulation-wherein the emphasis is on the application and integration of knowledge, skills and critical thinking is the best method. ACLS simulators allow learners to practise psychomotor skills and receive feedback on performance. ${ }^{[8]}$ Simulation is an effective teaching strategy to train CPR knowledge and skills. ${ }^{[9,10]}$ In this study, we used the simulator, Heartsim 4000 Interactive ACLS Mannequin to train nurses on basic and ACLS skills.

The duration of the CPR training program in literature has varied from $2 \mathrm{~min}$ "booster" training ${ }^{[11]}$ to $45 \mathrm{~min},{ }^{[12,13]}$ $180 \mathrm{~min}^{[13]}$ or even up to $4 \mathrm{~h} \cdot{ }^{[14]}$ Sodhi et al., $2011^{[5]}$ reported the impact of AHA-certified BLS and ACLS provider course of 3 days duration. However, a comprehensive CPR training program of $20 \mathrm{~h}$ (10 days) similar to ours could not be found. Skill evaluation is usually done soon after the training as well as at 70 days, ${ }^{[14]} 3$ months, ${ }^{[4]}$ 6 months, ${ }^{[4,13]} 9$ months, ${ }^{[4]} 1$ year ${ }^{[4,13]}$ and 18 months $^{[15]}$ after initial training. Our setting is different, and we have tested only the salient knowledge aspects; that too 3-4 years after the initial training.

The CPR certified nurses in this study perceived that they benefited from this training program regarding knowledge, skill, attitude, confidence, and communication skill. There were three reported incidents of commendable CPR skills being demonstrated by the participants, during in and out-of-hospital cardiac arrests, saving lives of patients and the general public since cardiac arrests can happen anywhere, anytime. Prior training helps in an improved rate of successful resuscitation. Formal certified BLS and ACLS training courses with the hands-on practice improved rate of immediate survival and survival to hospital discharge rates leading to definitive improvement in the outcome of CPR.${ }^{[5]}$ Although the quality of CPR improved after implementing 2005 guidelines, only a weak trend in improved survival to hospital discharge following cardiac arrest was seen ${ }^{\left[{ }^{[6]}\right.}$ Even with monthly practice and accurate voice-activated manikin feedback, some nursing students could not perform CPR correctly. ${ }^{[17]}$

In phase one, there was a statistically significant increase in mean posttest CPR knowledge, and overall performance. These results are consistent with previous 
research studies that there is posttest increase in CPR knowledge ${ }^{[15,18]}$ and quality. ${ }^{[11]}$ However, CPR skills deteriorate over a period of 1 year. Retention of both basic $^{[19,20]}$ and advanced resuscitation skills is short. ${ }^{[4]}$ Advanced life support (ALS) knowledge and skills decay by 6 months to 1 year after training and the skills decay faster than knowledge. ${ }^{[6,21,22,23]}$ Allen et al..$^{[21]}$ also reported that there was no correlation between theoretical knowledge and resuscitation performance. However, in this study, a significant correlation was seen between resuscitation knowledge and performance in phase one. A significant positive correlation was seen between pretest and retest also. However, we did not conduct a performance test in phase two which is conducted 3-4 years after initial CPR training, a limitation in this study. Nevertheless, the reported success rate of CPR was high and similar in both the CPR certified and noncertified groups, probably due to the team effort and availability of CPR certified nurses in each unit.

The knowledge range of CPR in retest underscores the fact that self-motivation is a significant factor in acquiring and retaining knowledge. CPR competence remains an important individual and institutional motivational challenge. ${ }^{[23]}$ The certified nurses' mean CPR knowledge, though higher than the noncertified nurses, did not show a statistically significant increase, indicating the need for periodic and more frequent refresher training for sustained improvement in knowledge and skill. Delivering ALS education more frequently than annually would increase skills maintenance and lessen skill decays. ${ }^{[24]}$ As suggested by the majority of the participants periodic training is necessary at least every year.

The study results are limited to a single institute, the retest knowledge test could not be conducted similar to the pretest and performance test could not be repeated due to time constraints.

\section{Conclusion}

There is a role for CPR training and certification in life support programs. This study showed that formal certified CPR training program using different teaching techniques enhanced nurses' knowledge, skill, attitude and overall confidence as well as helped to boost up their morale. It provided evidence that certified CPR training could increase the confidence of nurses to initiate timely CPR and saved lives even in out-of-hospital cardiac arrest situation where this counts a lot. However, presently we feel that formalized repetitive training on CPR should not be made mandatory. But one should look out for every opportunity to conduct such training program. The reason lies in the availability of human resources and adequate time. Both training staff and participants are taking their time outside their extended working hours. Once it is made mandatory and if these constraints are genuine, the whole exercise will be a failure. We strongly believe that training with evaluation increases the knowledge on resuscitation process and motivate the nurses to apply latest guidelines laid down by international bodies. With fairly flexible training process the knowledge base becomes more acceptable to the participants.

\section{Financial support and sponsorship \\ Nil.}

\section{Conflicts of interest}

There are no conflicts of interest.

\section{References}

1. Berg RA, Hemphill R, Abella BS, Aufderheide TP, Cave DM, Hazinski MF, et al. Part 5: Adult basic life support: 2010 American Heart Association Guidelines for Cardiopulmonary Resuscitation and Emergency Cardiovascular Care. Circulation 2010;122 18 Suppl 3:\$685-705.

2. Jensen ML, Lippert F, Hesselfeldt R, Rasmussen MB, Mogensen SS, Jensen MK, et al. The significance of clinical experience on learning outcome from resuscitation training-a randomised controlled study. Resuscitation 2009;80:238-43.

3. Brown TB, Dias JA, Saini D, Shah RC, Cofield SS, Terndrup TE, et al. Relationship between knowledge of cardiopulmonary resuscitation guidelines and performance. Resuscitation 2006;69:253-61.

4. Smith KK, Gilcreast D, Pierce K. Evaluation of staff's retention of ACLS and BLS skills. Resuscitation 2008;78:59-65.

5. Sodhi K, Singla MK, Shrivastava A. Impact of advanced cardiac life support training program on the outcome of cardiopulmonary resuscitation in a tertiary care hospital. Indian J Crit Care Med 2011;15:209-12.

6. Williams NM. Advanced life support, training and assessment: A literature review. Australas Emerg Nurs J 2011;14:240-5.

7. Robak O, Kulnig J, Sterz F, Uray T, Haugk M, Kliegel A, et al. CPR in medical schools: Learning by teaching BLS to sudden cardiac death survivors - A promising strategy for medical students? BMC Med Educ 2006;6:27.

8. Rauen CA. Simulation as a teaching strategy for nursing education and orientation in cardiac surgery. Crit Care Nurse 2004;24:46-51.

9. Hamilton R. Nurses' knowledge and skill retention following cardiopulmonary resuscitation training: A review of the literature. J Adv Nurs 2005;51:288-97.

10. Sullivan N. An integrative review: Instructional strategies to improve nurses' retention of cardiopulmonary resuscitation priorities. Int $\mathrm{J}$ Nurs Educ Scholarsh 2015;12:37-43.

11. Sutton RM, Niles D, Meaney PA, Aplenc R, French B, Abella BS, et al. "Booster" training: Evaluation of instructor-led bedside cardiopulmonary resuscitation skill training and automated corrective feedback to improve cardiopulmonary resuscitation compliance of pediatric basic life support providers during simulated cardiac arrest. Pediatr Crit Care Med 2011;12:e116-21.

12. Hirose T, Iwami T, Ogura H, Matsumoto H, Sakai T, Yamamoto K, et al. Effectiveness of a simplified cardiopulmonary resuscitation training program for the non-medical staff of a university hospital. Scand J Trauma Resusc Emerg Med 2014;22:31.

13. Nishiyama C, Iwami T, Kitamura T, Ando M, Sakamoto T, Marukawa S, 
et al. Long-term retention of cardiopulmonary resuscitation skills after shortened chest compression-only training and conventional training: A randomized controlled trial. Acad Emerg Med 2014;21:47-54.

14. Madden C. Undergraduate nursing students' acquisition and retention of CPR knowledge and skills. Nurse Educ Today 2006;26:218-27.

15. Hammond F, Saba M, Simes T, Cross R. Advanced life support: Retention of registered nurses' knowledge 18 months after initial training. Crit Care Resusc 2000;13:99-104.

16. Olasveengen TM, Vik E, Kuzovlev A, Sunde K. Effect of implementation of new resuscitation guidelines on quality of cardiopulmonary resuscitation and survival. Resuscitation 2009;80:407-11.

17. Kardong-Edgren S, Oermann MH, Odom-Maryon T. Findings from a nursing student CPR study: Implications for staff development educators. J Nurses Staff Dev 2012;28:9-15.

18. Passali C, Pantazopoulos I, Dontas I, Patsaki A, Barouxis D, Troupis G, et al. Evaluation of nurses' and doctors' knowledge of basic \& advanced life support resuscitation guidelines. Nurse Educ Pract 2011;11:365-9.

19. Partiprajak S, Thongpo P. Retention of basic life support knowledge, self-efficacy and chest compression performance in Thai undergraduate nursing students. Nurse Educ Pract 2016;16:235-41.

20. Mardegan KJ, Schofield MJ, Murphy GC. Comparison of an interactive CD-based and traditional instructor-led basic life support skills training for nurses. Crit Care Resusc 2015;28:160-7.

21. Yang CW, Yen ZS, McGowan JE, Chen HC, Chiang WC, Mancini ME, et al. A systematic review of retention of adult advanced life support knowledge and skills in healthcare providers. Resuscitation 2012;83:1055-60.

22. Allen JA, Currey J, Considine J. Annual resuscitation competency assessment: A review of the evidence. Crit Care Resusc 2013;26:12-7.

23. Mpotos N, Decaluwe K, Van Belleghem V, Cleymans N, Raemaekers J, Derese A, et al. Automated testing combined with automated retraining to improve CPR skill level in emergency nurses. Nurse Educ Pract 2015;15:212-7.

24. Taplin J, McConigley R. Advanced life support (ALS) instructors experience of ALS education in Western Australia: A qualitative exploratory research study. Nurse Educ Today 2015;35:556-61. 